\title{
Prevalence of Diabetes among Children of Insulin-dependent Diabetic Mothers
}

\author{
J. Köbberling and B. Brüggeboes \\ Department of Medicine, University of Göttingen, Göttingen, FRG
}

Summary. Eight diabetics were found among 464 children, mean age 11.2 years, of 311 unselected insulin-treated mothers. By a method of age correction the total diabetes prevalence among the children at the age of 25 years was calculated as $3.4 \%$. Three children were non-insulin dependent and these patients and their mothers may belong to the autosomal dominant type of diabetes, so-called MODY. In two of the other five families the fathers also had insulin-dependent diabetes; in two more cases first or second degree paternal relatives were insulin-dependent diabetics. Thus the prevalence of insulin-dependent diabetes among the children of insulin dependent mothers married to non-diabetics is calculated as $1.5 \%$ at the age of 25 years.

Key words: Insulin-dependent diabetes, MODY, familial diabetes, genetics.

Collected family data are not a suitable basis for genetic counselling of insulin-dependent diabetic patients about the risk of their children developing diabetes. Few studies are available in which the risk for the children has been directly calculated from empirical data $[2,5-9,13]$. The results have varied between $0.2 \%$ and $8 \%$, probably due to different methods of selection. In some of these studies data were combined for siblings and children and in most the mothers were not selected as being insulindependent. In addition, with exception of the study by Degnbol and Green [6] no corrections were made for the varying age of the children.

The present study was performed to gain information about the prevalence of diabetes among the children of insulin-dependent mothers. Such preva- lence figures should allow one to calculate the risk of the children developing diabetes within the first 25 years of life.

\section{Patients and Methods}

Four hundred and seventy three diabetic women were traced who had been treated during pregnancy by diabetic clinics or obstetric departments from nine German Universities (Kiel, Hamburg, Hannover, Göttingen, Bonn, Cologne, Giessen, Frankfurt, Würzburg). In addition, 70 women were contacted through a lay organisation for diabetics. Of the total, 49 women $(=9.0 \%)$ had either died or their addresses could not be found and $101(=18.6 \%)$ refused to answer the questionnaire. The 311 of the remaining 393 women included in the study 1) had been treated with insulin within 6 months of the diagnosis of diabetes and ever since, 2) were treated with insulin before conception, and 3) had given birth to at least one child living longer than 6 months. The mean age at diagnosis of the diabetes in the mothers was 15.2 years.

For the age correction, a method described by Köbberling [10] was used. The relative risk of having developed diabetes at any particular age can be calculated for all those who will have diabetes at the age of 25 years. For the present study these relative risk figures have been calculated from the incidence data published by Christau et al. [3] (Fig. 1). Very similar curves are obtained using data from other authors $[1,15]$ but only Christau et al. have published reliable incidence data up to the age of 25 years. The respective value for each child was calculated according to Figure 1, thus giving an "age reduced" total number of children. The 7 children at the age of 20 years, for example, were calculated as 7 times 0.82 $=5.7$ "age reduced" children whereas the 17 children at the age of 5 years only amounted to 17 times $0.12=2.0$ "age reduced" children. The number of diabetic children divided by the age reduced total number yields the calculated prevalence of diabetes among the children under the assumption that all of them will reach the age of 25 years.

\section{Results}

Information was obtained from 464 children with a mean age of 11.2 years. The age distribution of the children can be seen from the life table in Figure 2. 


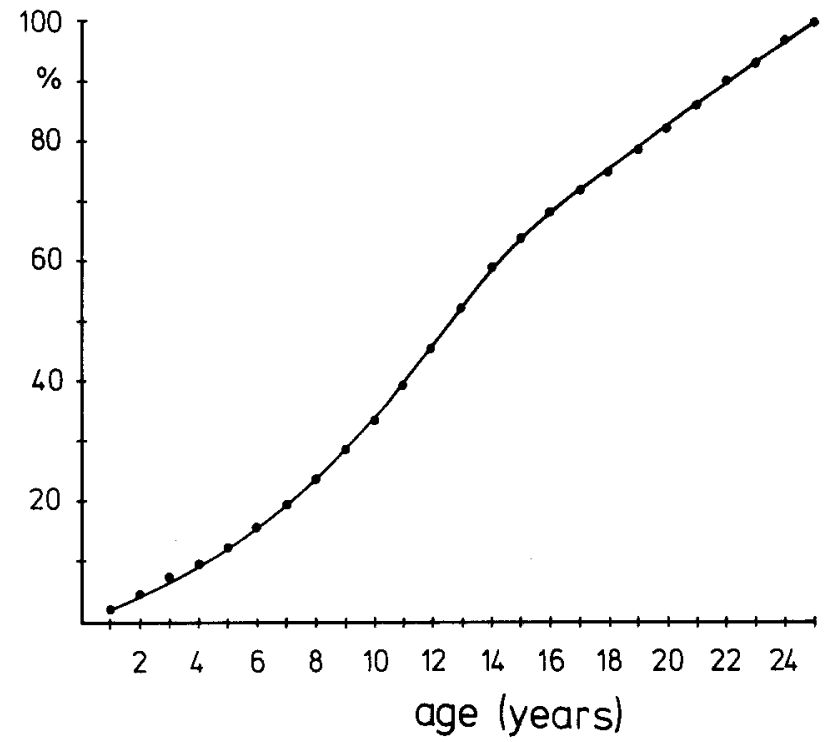

Fig. 1. Cumulative risk of developing diabetes up to the age of 25 years. This curve has been calculated using incidence data published by Christau et al. [3]

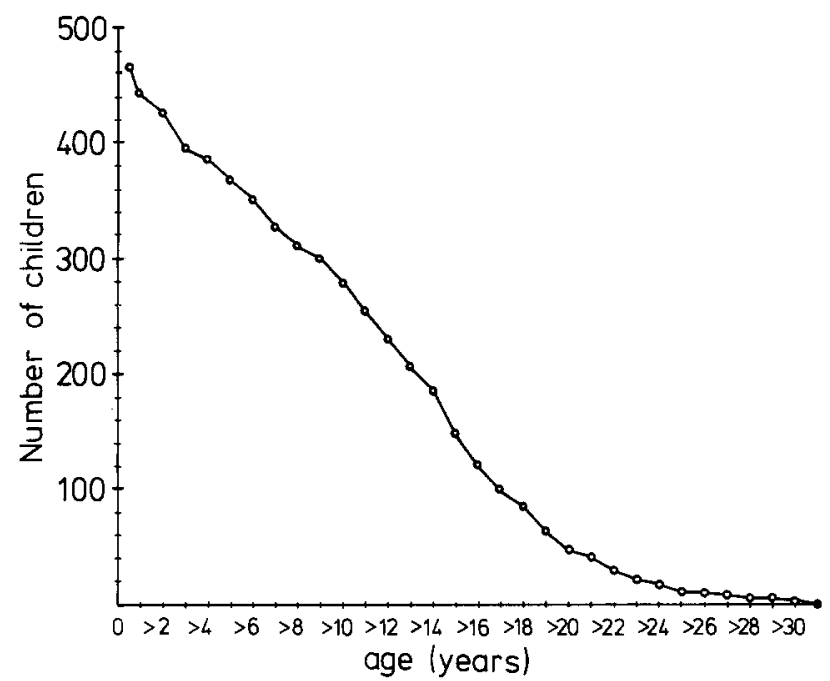

Fig. 2. Life table of 464 children of insulin dependent diabetic mothers. The numbers indicate the children who had been at risk at each particular age

Table 1. Present age (years) and age at onset of diabetes of the mothers and the diabetic children from the families shown in Figure 3

\begin{tabular}{crrrrrrrr}
\hline & \multicolumn{1}{c}{ Family } & & & & & \\
\cline { 2 - 8 } & I & II & III & IV & V & VI & VII & VIII \\
\hline Mothers, present age & 37 & 52 & 57 & 38 & 43 & 54 & 34 & 41 \\
age at onset (years) & 3 & 17 & 34 & 12 & 14 & 27 & 17 & 12 \\
Child, present age & 5 & 24 & 32 & 13 & 16 & 19 & 7 & 19 \\
age at onset (years) & 2 & 4 & 31 & 8 & 6 & 6 & 3 & 6 \\
\hline
\end{tabular}
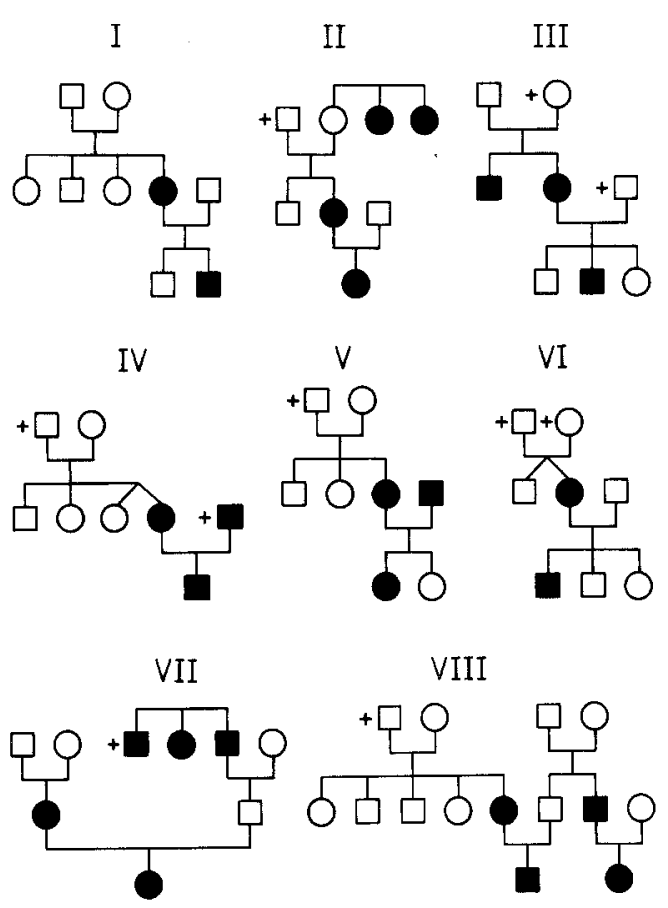

Fig. 3. Pedigrees of 8 families in whom a child of the insulindependent diabetic mother has developed non-insulin dependent (I-III) or insulin-dependent (IV-VIII) diabetes. $+=$ deceased

Eight children were reported to have diabetes (Fig. 3). Their ages at the time of the survey and ages at onset of diabetes and that of their mothers are shown in Table 1.

Three diabetic children (families I, II and III) have been treated without insulin for 3,20 and 1 years respectively (Table 1 ). Further diabetic members in two of these families developed the disease after the age of 50 years and have never been treated with insulin. Ketoacidosis has never occured in the three mothers. In spite of a long duration of diabetes, the mothers of family I and III were treated with relatively low daily doses of insulin (20 and 24 IU per day respectively).

Two of the diabetic mothers with affected children were married to an insulin-dependent diabetic husband (families IV and V). We have only seen this occur in one further family with a non-diabetic nine year old daughter. The mother in family IV has a non-diabetic dizygotic twin sister.

In the remaining three families, diabetes occurred in the families of two of the husbands. In family VII the father and the aunt of the husband developed non-insulin dependent diabetes at an older age, and the uncle was treated with insulin for an unknown period. In family VIII the brother and the niece of the husband developed insulin-dependent diabetes at the age of 40 and 12 years respectively. 
For the calculation of expected diabetes prevalence at the age of 25 years family III was excluded since diabetes was not diagnosed until the age of 31 years. The age reduced total number of children (referred to the age of 25 years) has been calculated as 207 . The overall prevalence of diabetes at the age of 25 years is therefore $7 / 207=3.4 \%$. Excluding all children from conjugal diabetic parents the prevalence was only $5 / 205=2.4 \%$. The total prevalence of insulin-dependent diabetes was $5 / 207=2.4 \%$. The prevalence of insulin-dependent diabetes among children of mothers not married to a diabetic husband was $3 / 205=1.5 \%$.

The diabetic mothers reported insulin-dependent diabetes among their parents in $1.0 \%$ and non-insulin-dependent diabetes in $9.8 \%$. Seventeen siblings of the mothers have insulin-dependent diabetes, a prevalence of $3.2 \%$ at the age of 25 years.

A computer printout with detailed data from all 311 mothers, their parents and siblings and the 464 children may be obtained on request from the first author.

\section{Discussion}

The results of the present study confirm that the risk of offspring of insulin-dependent mothers developing diabetes is very low. For the purpose of genetic counselling the risk can be summarised as about 2 to $3 \%$ (including non-insulin dependent diabetics) if the husband does not have diabetes. This is similar to the figure of $2.8 \%$ at the age of 25 years calculated by Degnbol et al. [6] using a different method. Recalculation of the data from these authors with the method used by us yielded a prevalence of $3 \%$ at the age of 25 years. No exact figures can be given for the risk of developing diabetes later in life but it is probably also very low. Maturity onset type diabetes will probably develop in these offspring with the same frequency as the ordinary population [11]. That diabetes is a "hereditary disorder" should therefore not influence family planning to a great extent in patients with insulin-dependent diabetes.

The observation that in two of three families with conjugal insulin-dependent diabetes, a child has developed the same disease suggests a much higher risk for these children. The numbers are too small to calculate risk figures but the deviation in diabetes incidence among offspring from that in non conjugal families is unlikely to be due to chance. No other data are available in the literature about the risk in families where both parents have insulin-dependent diabetes. Data from unselected diabetics $[4,14]$ do not help to answer this question. If further studies establish a more than additive risk in conjugal families this would support the concept of recessive genes playing a role in the aetiology of the classical juvenile type of diabetes [12]. The fact that in two of the remaining three families with insulin-dependent children (VII and VIII) insulin-treated diabetes occurred in the families of the fathers is interesting.

The three children with non-insulin dependent diabetes with a duration of diabetes between 1 and 20 years have to be assigned to the maturity onset type diabetes in young people, called MODY [16]. This type of diabetes is characterised by an autosomal dominant inheritance and familial occurrence is therefore often observed. None of the three mothers has ever experienced ketoacidosis. It is therefore probable that these mothers, in spite of being treated with insulin for 23,34 and 35 years, belong to the non insulin-dependent type of diabetes. Further investigation is needed to qualify the estimation of individual risk figures in genetic counselling. It is not improbable that the risk for children of truly insulin-dependent mothers is even lower than has been calculated from the results of this study.

Acknowledgement. This study was supported by a grant from the Deutsche Forschungsgemeinschaft (Ko 457/9).

We thank the following colleagues who have allowed us to study hospital records or have helped to find out addresses of diabetic mothers: Dr. O. Bellmann, Bonn; Prof. A. Bolte, Cologne; Prof. W. Creutzfeldt, Dr. U. Deuticke, Göttingen; Dr. A. Feige, Würzburg; Prof. J. Kühnau, Hamburg; Prof. W. Kuhn, Göttingen; Dr. R. Petzold, Frankfurt; Prof. J. Plotz, Bonn; Dr. R. Rauskolb, Giessen; Dr. H. F. Schäfer, Prof. K. Schöffling, Frankfurt; Prof. K. Semm, Kiel; Dr. E. Standl, Munich; Prof. K. H. Wulf, Würzburg.

\section{References}

1. Bloom A, Hayes TM, Gamble DR (1975) Register of newly diagnosed diabetic children. Br. Med J III: $580-583$

2. Breidahl HD (1966) The growth and development of children born to mothers with diabetes. Med J Aust 1: 268-270

3. Christau B, Kromann H, Andersen O, Christy M, Buschard K, et al (1977) Incidence, seasonal and geographical pattern of juvenile-onset insulin-dependent diabetes mellitus in Denmark. Diabetologia 13: 281-284

4. Cooke AM, Fitzgerald MG, Malins JM, Pyke DA (1966) Diabetes in children of diabetic couples. Br Med J II: 674-676

5. Darlow JM, Smith C, Duncan LJP (1973) A statistical and genetical study of diabetes. III. Empiric risks to relatives. Ann Hum Genet 37: 157-173

6. Degnbol B, Green A (1978) Diabetes mellitus among firstand second-degree relatives of early onset diabetics. Ann Hum Genet 42: 25-47

7. Farguhar JW (1969) Prognosis for babies born to diabetic mothers in Edinburgh. Arch Dis Child 44: 36-47

8. Hagbard L, Olow J, Reinard T (1959) A follow-up study of 514 children of diabetic mothers. Acta Paediatr Scand 48: 184-197

9. Hiekkala H, Koskenoja M (1961) A follow-up study of children of diabetic mothers. Part I. Ann Paediatr Fenn 7: 17-31 
10. Köbberling J (1969) Untersuchungen zur Genetik des Diabetes mellitus. Eine geeignete Methode zur Durchführung von Alterskorrekturen. Diabetologia 5: 392-396

11. MacDonald MJ (1974) Equal incidence of adult-onset diabetes among ancestors of juvenile diabetics and nondiabetics. Diabetologia 10: 767-773

12. Rubinstein P, Suciu-Foca N, Nicholsen JF (1977) Genetics of juvenile diabetes mellitus. N Engl J Med 297: 1036-1040

13. Schwaninger D (1973) Katamnestische Untersuchungen von Kindern diabetischer Mütter. Schweiz Med Wochenschr 103: $1130-1134$

14. Simpson N E (1968) Diabetes in the families of diabetics. Can Med Assoc J 98: 427-432

15. Sterky G, Holmgren G, Gustavson $\mathrm{KH}$, Larsson Y, Lundmark KM, et al (1978) The incidence of diabetes mellitus in Swedish children 1970-1975. Acta Paediatr Scand 67: 139-143
16. Tattersall RB, Fajans SS (1975) A difference between the inheritance of classical juvenile-onset and maturity-onset type diabetes of young people. Diabetes 24: 44-53

Received: September 4, 1979,

and in revised form: December 21, 1979

Prof. Dr. J. Köbberling

Medizinische Universitätsklinik

Robert-Koch-Straße 40

D-3400 Göttingen

Federal Republic of Germany 